\title{
Tumor Response and Factors Affecting Survival of Using Sorafenib in Management of Advanced Hepatocellular Carcinoma
}

\author{
Ahmed Ramadan', Tamer Mahmoud Elbaz ${ }^{1}$, Ashraf Omar Abdelaziz', Mohamed Mahmoud \\ Nabeel $^{1}$, Ahmed Hosni Abdelmaksoud ${ }^{2}$, Hend Ibrahim Shousha ${ }^{1 *}$, Wafaa Elakel ${ }^{1}$, Zeinab \\ Soliman ${ }^{1}$, Eman Medhat ${ }^{1}$, Dalia Omran ${ }^{1}$, Rania mohamed Lithy ${ }^{1}$, Hedy A Badary ${ }^{1}$ and Samar \\ Samir Youssef ${ }^{3}$ \\ ${ }^{1}$ Endemic medicine department, Faculty of medicine, Cairo University, Cairo, Egypt \\ ${ }^{2}$ Diagnostic and interventional radiology department, Faculty of medicine, Cairo University, Cairo, Egypt \\ ${ }^{3}$ Biomedical technology, Microbial Biotechnology Department, Genetic engineering and biotechnology division, National research Centre, \\ Cairo, Egypt
}

*Corresponding author: Hend Ibrahim Shousha, Endemic medicine Department, Faculty of Medicine, Cairo University, Egypt

\section{ARTICLE INFO}

Received: April 19, 2021

Published: 幽 May 03, 2021

Citation: Hend Ibrahim S, Ahmed r, Tamer Mahmoud E, Ashraf Omar A, Mohamed Mahmoud N, et al., Tumor Response and Factors Affecting Survival of Using Sorafenib in Management of Advanced Hepatocellular Carcinoma. Biomed J Sci \& Tech Res 35(3)-2021. BJSTR. MS.ID.005713.

Keywords: Hepatocellular Carcinoma; Sorafenib; Survival; Predictor of Survival

\section{ABSTRACT}

Purpose: Hepatocellular carcinoma (HCC) is a dismal tumor that is usually diagnosed at late stages. Sorafenib is the main line of treatment in advanced HCC cases while preserved hepatic functions. However, the drug has high costs and is associated with several side effects. We aimed to study the predictive factors for survival to limit patients with potential low response and exposure to side effects.

Methods: This prospective cohort study included 64 patients with advanced HCC and who were treated using Sorafenib according to international guidelines. The modified Response evaluation criteria in solid tumors (RECIST) assessed treatment response and we did regression analysis for predictors of survival.

Result: Our studied patients were predominantly males with mean age 59 years. They were Child A (48 patients) and Child B7 (16 patients). Lesions were large in size (mean $6.5 \mathrm{~cm}$ ) and 50\% had portal vein thrombosis. Stationary disease was recorded in $84.38 \%$ of patients with a mean duration of treatment 4.71 months and overall survival $11.25 \pm 7.25$ months. Hand and foot syndrome was the most common adverse event. Multivariate regression analysis showed that performance status (HR: 2.96, CI: (1.227.21), P-value 0.02) and tumor size $\geq 5 \mathrm{~cm}$ (HR: 2.36, CI: (1.1-5.25) P-value 0.03) were the lone factors.

Conclusion: We reported higher rates of stationary disease and good survival rates. The lone prognostic factors for survival were PS $\geq 2$ and size of lesions $\geq 5 \mathrm{~cm}$. Sorafenib is still a backbone treatment for advanced HCC patients till emergence of safer and more effective lines of treatment.

\section{Introduction}

Hepatocellular carcinoma (HCC) is the most common primary liver malignancy and the second leading cause of cancer related death worldwide [1]. The estimated incidence is $5-6 \%$ of all new cancers [2]. Due to complexity of HCC management, due to presence of multiple factors related to the malignancy and the underlying liver disease, proper management requires a multidisciplinary approach [3]. HCC is famous with its poor prognosis. This is mostly related to the aggressive biological behavior, rapid progression and the underlying chronic liver disease [4]. In clinical practice, more than $60 \%$ of HCC cases are diagnosed at late stages [5]. A restricted 
number of patients with early lesions have a chance for curative treatment such as liver transplantation and hepatic resection [6]. Also, portal vein thrombosis (PVT) is diagnosed in up to $40 \%$ of HCC patients when firstly presented [7].

Sorafenib, a multi kinase inhibitor, was the first drug to receive FDA approval for a beneficiary survival rate in patients with advanced HCC. Two major randomized controlled trials concluded an improved median overall survival by 2-3 months when compared to placebo $[8,9]$. Sorafenib became the standard of care treatment for advanced HCC with preserved hepatic functions. However, survival benefit proved to vary widely between individuals [10]. In addition, the drug is expensive and is associated with adverse events. For such results, it is better to determine HCC cases who may benefit from Sorafenib therapy and spare patients who are potentially resistant and got exposed to unnecessary toxicity [11]. As no validated biomarkers were proved to predict response to Sorafenib therapy, different parameters were studied for possible predicted values [12]. GIDEON study documented a strong predictive role to albumin and bilirubin [13]. ECOG performance status more than 0, older age than 72 years, presence of macrovascular invasion and presence of numerous focal lesions more than 7 lesions were predictive factors for poor prognosis in advanced HCC patients treated with Sorafenib [14]. Child Pugh score, BCLC stage and occurrence of significant side effects were similarly proposed as main prognostic factors [15]. With absence of clear and validated prognostic factors, we aim in our study to determine the different prognostic factors that are related to Sorafenib use in management of advanced HCC and impact of Sorafenib on overall survival of studied patients.

\section{Patients and Methods}

During the period September 2012 and June 2016, 1221 HCC patients were managed in our multidisciplinary clinic for HCC, Cairo University, Egypt. Among those patients, 64 cases received Sorafenib according to EASL guidelines and AASLD practice guidelines for management of HCC $[16,17]$ and in respect to ethics principles of the Declaration of Helsinki with Good Clinical Practice guidelines. Included patients were BCLC - C with preserved liver profile (Child Pugh class up to B7). According to guidelines, we excluded patients with curative potentials (BCLC A and B) and patients with evidence of hepatic decompensation (late Child B and Child C).

Concerning Sorafenib intake, we requested the patients to start with $200 \mathrm{mg}$ twice a day and we rose the dose to $400 \mathrm{mg}$ twice a day (full dose) after two weeks. Thereafter, dose modifications were related to frequency and intensity of adverse events. Patients were scheduled for follow up two weeks after starting treatment then every month for first three months then fixed every three months. Sorafenib was stopped whenever serious adverse events occurred, non-tolerability of the patients and/or marked clinical disease or radiological progressions were documented. During the follow up visits, patients were assessed for safety and efficacy of the drug.
Patients are questioned for potential side effects such as fatigue, diarrhea, skin manifestations that are compatible with hand and foot syndrome. Laboratory investigations include complete blood picture (CBC), liver biochemical profile (total bilirubin, serum albumin, INR and liver enzymes), renal profile and alpha fetoprotein (AFP). Imaging included triphasic CT abdomen or dynamic MRI liver. Assessment of efficacy was verified according to modified RECIST criteria (Response Evaluation Criteria in Solid Tumors [18]. Phone calls are performed for patients who missed their scheduled visits every six months. Overall survival was calculated as the total time between start of Sorafenib treatment and death.

Descriptive statistics were done, and categorical variables were presented as frequencies and percentages and numerical data as mean (SD) or median (IQR). Survival analysis was done and the median survival time of patients taking Sorafenib was determined. Univariable and multivariable Cox proportion hazard regression analysis was performed to investigate predictors of worse survival for patients on Sorafenib. P values $<0.05$ are deemed significant. STATA 15.1 was used for the analysis.

\section{Result}

In our retrospective study, we managed 64 patients with advanced HCC. They were 56 males and 8 females with a mean age 59 years. Chronic HCV was the dominant cause of underlying liver disease and cirrhosis. Majority of our studied patients were Child A (48 patients) while the rest were Child B7. In addition, $90.6 \%$ of patients were ECOG PS 0-1 (Table 1). Concerning baseline laboratory data, studied patients had normal mean levels of CBC parameters (hemoglobin, leucocytic count and platelets) and preserved synthetic and excretory hepatic functions (total bilirubin, albumin and INR). Otherwise, liver enzymes were mildly elevated, and the median AFP level was $290.95 \mathrm{ng} / \mathrm{ml}$. Regarding tumor data, $51.6 \%$ only had single tumors and the mean size was $6.25 \mathrm{~cm}$. Half of studied patients had evident macrovascular invasion (MVI) and significant metastatic lymphadenopathy was present in $18.75 \%$ of patients (Table 1).

Focusing on Sorafenib outcomes, $84.38 \%$ of patients showed a stationary disease (SD) course during the follow ups and the mean duration of treatment was 4.71 months. Clinical decompensation occurred in 22 patients. Side effects were documented in 46 patients who showed 53 events. Hand and Foot syndrome was the most frequent event $(32.8 \%)$ followed by fatigue $(28.1 \%)$, diarrhea (12.5\%), elevated liver enzymes (7.8\%) and jaundice (1.56\%). Mean overall survival was 11.25 months. By end of study, $57.8 \%$ of patients died while $42.8 \%$ remained alive (Table 2 ). We performed regression analysis for predictors of survival. Both PS $\geq 2$ and tumor size $\geq 5 \mathrm{~cm}$ were the lone factors to correlate with survival in univariate and multivariate analyses. Age, gender, MVI, lymphadenopathy, high AFP (>200ng/ml) did not correlate with survival in patients managed with Sorafenib (Table 3) (Figure 1). 
Table 1: Demographic, laboratory and tumor baseline characteristics.

\begin{tabular}{|c|c|}
\hline Characteristics $(\mathrm{N}=64)$ & Results \\
\hline \multicolumn{2}{|c|}{ Baseline Data } \\
\hline Age (years) & $59.05 \pm 7.21$ \\
\hline Sex (male/female) & $56 / 8$ \\
\hline Smoking & $32(50 \%)$ \\
\hline Diabetes Mellitus & $12(18.75 \%)$ \\
\hline Family history & $4(6.25 \%)$ \\
\hline Virology (HCV Ab/HBcTotal /HBsAg) & $53 / 1 / 0$ \\
\hline Child Score (A / B7) & $48 / 16$ \\
\hline Performance status $(0 / 1 / 2 / 3)$ & $36 / 22 / 4 / 2$ \\
\hline \multicolumn{2}{|c|}{ Laboratory Data } \\
\hline Hemoglobin & $12.69 \pm 1.81$ \\
\hline Leucocytic count & $6.14 \pm 2.71$ \\
\hline Platelets & $166.42 \pm 78.21$ \\
\hline Bilirubin Total & $1.28 \pm 0.69$ \\
\hline ALT & $67.95 \pm 50.18$ \\
\hline AST & $89.09 \pm 69.19$ \\
\hline Albumin & $3.48 \pm 0.55$ \\
\hline INR & $1.19 \pm 0.17$ \\
\hline Alpha fetoprotein & $290.95(1.7-391700)$ \\
\hline \multicolumn{2}{|c|}{ Imaging Data } \\
\hline Number of focal lesions (single/two /multiple) & $33 / 5 / 26$ \\
\hline Size of focal lesions & $6.25(1.5-15)$ \\
\hline Site of focal lesions (Rt lobe/Lt lobe/ Bilobar) & $46 / 4 / 14$ \\
\hline Portal vein (Patent/Thrombosed) & $32 / 32$ \\
\hline Lymphadenopathy (Yes/No) & Dec-52 \\
\hline
\end{tabular}

Table 2: Sorafenib treatment outcomes in studied patients.

\begin{tabular}{|c|c|}
\hline \multicolumn{1}{|c|}{ Outcomes } & \multicolumn{2}{c|}{ Results } \\
\hline$\varnothing$ Partial response of Disease & $1(1.56 \%)$ \\
\hline$\varnothing$ Stationary disease & $54(84.38 \%)$ \\
\hline$\varnothing$ Progressive disease & $9(14.06 \%)$ \\
\hline Duration of treatment (months) & $4.71 \pm 2.14$ \\
\hline Survival (months) & $11.25 \pm 7.25$ \\
\hline$\varnothing$ Dead by end of the study & $37(57.81 \%)$ \\
\hline$\varnothing$ Alive by end of the study & $27(42.19 \%)$ \\
\hline Clinical decompensation & $22(34.38 \%)$ \\
\hline Side effects & $46(71.88 \%)$ \\
\hline$\varnothing$ Hand and foot syndrome & $21(32.81 \%)$ \\
\hline$\varnothing$ Fatigue & $18(28.13 \%)$ \\
\hline$\varnothing$ Diarrhea & $8(12.5 \%)$ \\
\hline$\varnothing$ Elevated liver enzymes & $5(7.81 \%)$ \\
\hline$\varnothing$ Jaundice & $1(1.56 \%)$ \\
\hline
\end{tabular}


Table 3: Cox proportional hazard regression for studied patients.

\begin{tabular}{|c|c|c|c|c|}
\hline & \multicolumn{2}{|c|}{ Univariable Regression } & \multicolumn{2}{|c|}{ Multivariable Regression } \\
\hline & HR (95\% Conf. Interval) & P Value & HR (95\% Conf. Interval) & P Value \\
\hline Age & $0.98(0.94-1.03)$ & 0.5 & & \\
\hline \multicolumn{5}{|l|}{ Gender } \\
\hline Female & $1.30(0.54-3.15)$ & 0.5 & & \\
\hline Smoking & $0.99(0.52-1.92)$ & 0.99 & & \\
\hline Diabetes & $1.50(0.68-3.34)$ & 0.3 & & \\
\hline Performance status $\geq 2$ & $2.79(1.16-6.76)$ & 0.02 & $2.96(1.22-7.21)$ & 0.02 \\
\hline Child-Pugh class & $0.91(0.42-1.98)$ & 0.8 & & \\
\hline \multicolumn{5}{|l|}{ B } \\
\hline Lesion size $\geq 5 \mathrm{~cm}$ & $2.27(1.03-5.01)$ & 0.04 & $2.36(1.1-5.25)$ & 0.03 \\
\hline Number of focal lesions & $1.17(0.83-1.65)$ & 0.4 & & \\
\hline Portal vein thrombosis & $1.35(0.69-2.62)$ & 0.4 & & \\
\hline Presence of lymphadenopathy & $0.68(0.28-1.65)$ & 0.4 & & \\
\hline $\mathrm{AFP}>200$ & $1.22(0.63-2.37)$ & 0.5 & & \\
\hline
\end{tabular}

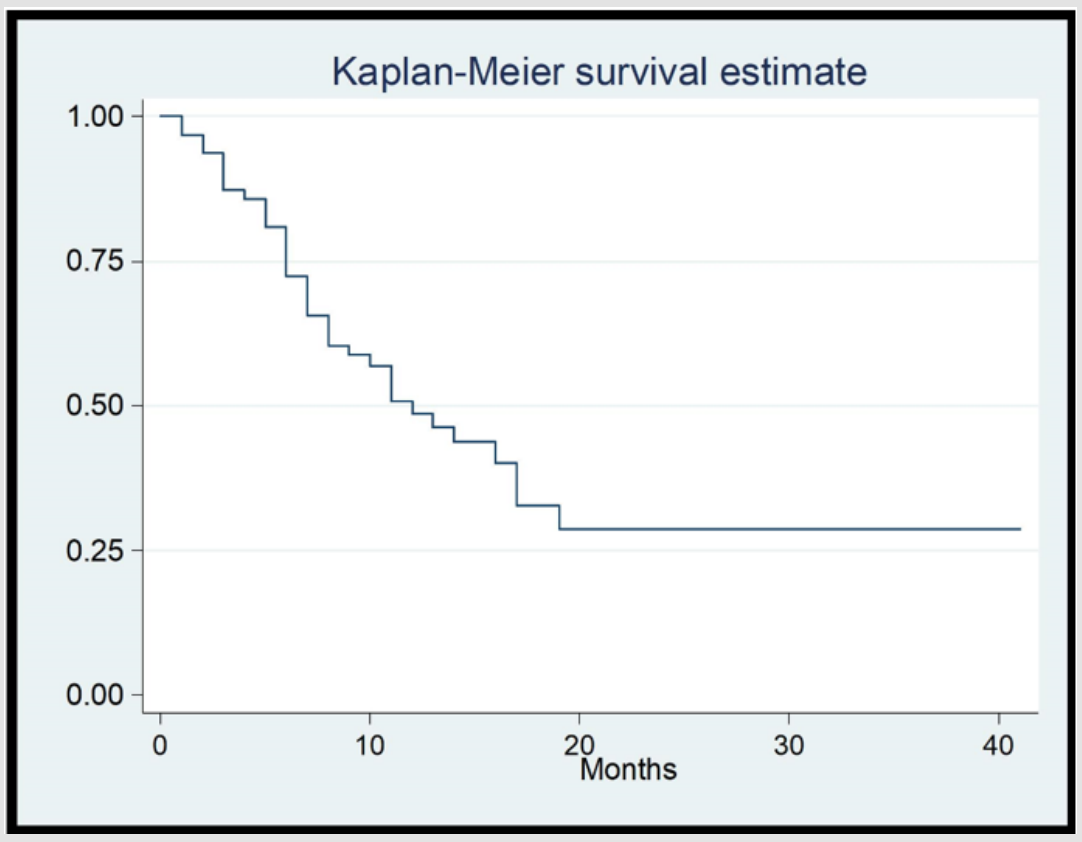

Figure 1: Kaplan Meier Curve for Survival of the studied patients.

\section{Discussion}

Since the introduction of Sorafenib in the management of advanced HCC, numerous studies tried to identify prognostic factors to avoid unnecessary side effects of the drug in potentially non-responding patients. None of the prognostic factors and systems proved to be optimal in prediction of survival in such patients [19]. In our multidisciplinary HCC clinic, we enrolled our study that included advanced HCC patients with preserved hepatic condition. They were BCLC - patients with large sized multi lesions with/without portal vein invasion and/or lymphadenopathy. As risk factors for HCC, majority of our patients were $\mathrm{HCV}$ positive and $18.75 \%$ were diabetics.
Notably, $84.4 \%$ of our studied patients had a stationary course while minorities (14\%) were progressive. These results are more beneficiary than previously reported (SD 46.7\%-51.6\% and PD $33.3 \%-44.4 \%$ ] [20, 21]. Mean duration of treatment was 4.71 months. Ye et al reviewed Chinese patients included in GIDEON study and mentioned that duration of therapy ranged between 18.8 and 21.1 weeks according to Child Pugh score [22]. Apostolidis et al found that continuing Sorafenib beyond progression for more than three months provided improved survival rates as compared to discontinuation within three months [23]. They also added that patients with poor prognosis and continued Sorafenib beyond progression had significantly prolonged survival. In agreement, 
Otsuka et al proved an advantage to continue Sorafenib even beyond progression disease and improvement of overall survival as compared to best supportive care [24]. Moreover, Cardoso et al concluded that increasing time of exposure of the drug and trying to reduce dose rather than to discontinue the drug if side effects occurred will improve survival of patients [15].

As we managed Child A-B7 patients with good performance status and we tried to prolong duration of treatment for more than 3 months, this also impacted our survival rates (mean OS 11.25 months). The two benchmark studies of Sorafenib (SHARP trial and Asia Pacific trial) reported an OS 6.5 and 10.7 months as compared to placebo (4.2 and 7.9 months) [8,9]. Selection of patients for Sorafenib intake in context of their Child Pugh score, BCLC stage and the timing to start treatment is truly crucial. Ogasawara et al reported OS 15.3 months in early cases and 5.3 months in advanced cases [14]. Timing of start gave better survival rates if it was before progression to advanced stage. In another study, median OS was 17.3 months for Child A and 3.2 for Child B [15]. Due to poor outcomes of managing late Child B patients, we limited them to Child B7.

Our main goal was to determine predictors of survival among our HCC patients who were treated with Sorafenib. Performance status $\geq 2$ and size of focal lesions $\geq 5 \mathrm{~cm}$ were the lone factors while age, gender, smoking, diabetes mellitus, Child B score, portal vein invasion, lymphadenopathy and high AFP ( $>200 \mathrm{ng} / \mathrm{ml}$ ) had no roles. Revising the literature, we found a great heterogeneity of factors and still no unique factor was agreed by different trials. Better survival rates correlated with history of previous hepatic resection (2) and aetiology of chronic liver disease if it was alcoholism [2] or chronic HCV $[2,25,26]$. Poor survival was predicted in relation to age [14,27], gender [2], performance status [14,27], macrovascular invasion [14,27], extrahepatic spread [2,27] and large lesions $[14,27]$. As for laboratory factors, AST, total bilirubin, AFP and CA19-9 correlated with survival [2,10,14,21,27]. Body mass index, nutritional index and sarcopenia had their impact on survival [2, $21,28]$. Different prognostic systems such as PROSASH depended on different baseline variables and proved superior to other different scoring systems such as ALBI and JIS scores $[10,27]$. Still no single factor is agreed by all studies or mentioned clearly in guidelines to rely on while managing advanced HCC patients treated with Sorafenib.

In our study, main bulk of patients (71.88\%) reported sided effects. Hand and Foot syndrome was the most frequent adverse event followed by fatigue and diarrhea. Importantly, Cardoso et al mentioned that patients with side effects had longer survival rates [15]. This may be related to prolonged exposure to the drug either by prolonged duration of treatment or the application of full doses of Sorafenib. Di Costanzo and colleagues concluded that patients with adverse events had survival 8.8 months as compared to 5.4 months if no side effects [29]. Also, Reig et al. concluded that Hand and Foot syndrome was associated with better survival (18.2 months versus 10.1 months if it did not occur) [30].

\section{Conclusion}

In conclusion, to take home message, we managed advanced HCC patients with Sorafenib. We reported higher rates of stationary disease, prolonged duration of treatment (more than 3 months), high incidence of side effects and resultant good survival rates. The lone prognostic factors for survival were $\mathrm{PS} \geq 2$ and size of lesions $\geq 5 \mathrm{~cm}$. Sorafenib is still a backbone treatment for advanced HCC patients till emergence of safer and more effective lines of treatment of such drastic malignancy.

\section{Declarations}

\section{Funding}

The authors have no relevant financial or non-financial interests to disclose.

\section{Conflicts of Interest/Competing Interests}

The authors have no conflicts of interest to declare that are relevant to the content of this article.

\section{Ethics Approval}

(All procedures performed in studies involving human participants were in accordance with the ethical standards of Faculty of medicine, Cairo University research committee and with the 1964 Helsinki Declaration and its later amendments. The study was approved by the research ethics committee, Faculty of medicine, Cairo University)

\section{Consent to Participate}

Include appropriate statements. Consent to participate written informed consent was obtained from the participants.

\section{Consent for Publication}

$(\mathrm{N} / \mathrm{A})$

\section{Availability of Data and Material:}

The data that support the findings of this study are available on request from the corresponding author, [Shousha $\mathrm{HI}]$.

\section{Code Availability}

$\mathrm{N} / \mathrm{A}$

\section{Authors' Contributions}

Include appropriate statements.

Conceptualization: Samar Samir Youssef, Hend Ibrahim Shousha

\section{Methodology}

Mohamed Mahmoud Nabeel, Ahmed Hosni Abdelmaksoud, Hend Ibrahim Shousha 


\section{Formal Analysis}

Wafaa Elakel, Zeinab Soliman

\section{Writing - Original Draft Preparation}

Tamer Mahmoud Elbaz

\section{Writing - Review and Editing}

Ashraf Omar Abdelaziz, Wafaa Elakel, Zeinab Soliman, Mohamed Mahmoud Nabeel, Ahmed Hosni Abdelmaksoud, Samar Samir Youssef, Eman Medhat, Dalia Omran, Rania Lithy, Hend Ibrahim Shousha

\section{Funding Acquisition}

$$
\mathrm{N} / \mathrm{A}
$$

\section{Resources}

Hend Shousha.

\section{Supervision}

\section{Ashraf Omar Abdelaziz.}

\section{References}

1. Torre LA, Bray F, Siegel RL (2012) Global cancer statistics. CA Cancer J Clin 65(2): 87-108.

2. Nishikawa H, Nishijima N, Enomoto H, Azusa Sakamoto, Akihiro Nasu, et al. (2017) Predictive factors in patients with hepatocellular carcinoma receiving sorafenib therapy using time-dependent receiver operating characteristic analysis. J Cancer 8(3): 378-387.

3. Siddique O, Yoo ER, Perumpail RB, Perumpail BJ, Liu A, et al. (2017) The importance of a multidisciplinary approach to hepatocellular carcinoma. J Multidiscip Healthc 10: 95-100.

4. Abdelaziz AO, Shousha HI, Abdelmaksoud AH, Saad Y, Elbaz TM, et al (2018). A new prognostic score can predict survival after hepatocellular carcinoma treatment in a cohort of 1302 Egyptian hepatocellular carcinoma patients. Eur J Gastroenterol Hepatol 30(5): 514-519

5. Gomaa AI, Hashim MS, Waked I (2014) Comparing staging systems for predicting prognosis and survival in patients with hepatocellular carcinoma in Egypt (2014). PLoS One 9: 90929.

6. Abdelaziz AO, Abdelmaksoud AH, Nabeel MM, Shousha HI, Cordie AA et al. (2017) Transarterial Chemoembolization Combined with Either Radiofrequency or Microwave Ablation in Management of Hepatocellular Carcinoma. Asian Pacific Journal of Cancer Prevention 18(1): 189-194

7. Quirk M, Kim YH, Saab S, Edward Wolfgang Lee (2015) Management of hepatocellular carcinoma with portal vein thrombosis. World J Gastroenterol 21: 3462-3471.

8. Cheng A-L, Kang Y-K, Chen Z, et al (2009) Efficacy and safety of sorafenib in patients in the Asia-Pacific region with advanced hepatocellular carcinoma: a phase III randomised, double-blind, placebo-controlled trial. Lancet Oncol 10(1): 25-34.

9. Llovet JM, Ricci S, Mazzaferro V, Edward Gane, Jean-Frédéric Blanc, et al. (2008) Sorafenib in advanced hepatocellular carcinoma. N Engl J Med 359: 378-390.

10. Labeur TA, Berhane S, Edeline J, Blanc JF, Bettinger D, et al. (2020) Improved survival prediction and comparison of prognostic models for patients with hepatocellular carcinoma treated with sorafenib. Liver international 40(1): 215-228.
11. Marisi G, Cucchetti A, Ulivi P, Canale M, Cabibbo G, et al. (2018) Ten years of sorafenib in hepatocellular carcinoma: Are there any predictive and/ or prognostic markers? World J Gastroenterol. 24(36): 4152-4163.

12. Colagrande S, Inghilesi AL, Aburas S, Gian G Taliani, Cosimo Nardi, et al. (2016). Challenges of ad- vanced hepatocellular carcinoma. World J Gastroenterol 22(34): 7645-7659.

13. Marrero JA, Kudo M, Venook AP, Sheng-Long Ye 4, Jean-Pierre Bronowicki, et al. (2016) Observational registry of sorafenib use in clinical practice across Child-Pugh subgroups: the GIDEON study. J Hepatol. 65(6): 11401147.

14. Ogasawara S, Chiba T, Ooka Y, Suzuki E, Inoue M, et al. (2016) Analysis of Sorafenib Outcome: Focusing on the Clinical Course in Patients with Hepatocellular Carcinoma. PLoS One 11(8): e0161303.

15. Cardoso H, Alves AM, Marques M, Vale AM, Pereira P, et al. (2016) Hepatocellular Carcinoma Treatment with Sorafenib: Real-Life Evaluation of Prognostic Factors and a Practical Clue for Patient Management. GE Port J Gastroenterol 23(5): 243-248.

16. Bruix J, Sherman M, Llovet JM (2001) EASL Panel of Experts on HCC. Clinical management of hepatocellular carcinoma. Con- clusions of the Barcelona-2000 EASL conference. European Association for the Study of the Liver. J Hepatol 35(3): 421-430.

17. Bruix J, Sherman M (2011) American Association for the Study of Liver Diseases. Management of hepatocellular carcinoma: an update. Hepatology 53(3): 1020-1022.

18. Lencioni R, Llovet JM (2010). Modified RECIST (mRECIST) assessment for hepatocellular carcinoma. Semin Liver Dis 30: 52-60.

19. Samawi HH, Sim HW, Chan KK, Alghamdi MA, Lee-Ying RM, et al. (2018). Prognosis of patients with hepatocellular carcinoma treated with sorafenib: a comparison of five models in a large Canadian database. Cancer Med 7(7): 2816-2825.

20. Lee S, Kim BK, Kim SU, Park JY, Kim Do Y, et al. (2015) Early $\alpha$-fetoprotein response predicts survival in patients with advanced hepatocellular carcinoma treated with sorafenib. J Hepatocell Carcinoma 2: 39-47.

21. Hatanaka T, Kakizaki S, Uehara D, Nagashima T, Ueno T, et al. (2019). Impact of the Prognostic Nutritional Index on the Survival of Japanese Patients with Hepatocellular Carcinoma Treated with Sorafenib: A Multicenter Retrospective Study. Intern Med 58(13): 1835-1844.

22. Ye SL, Chen X, Yang J, Bie P, Zhang S, et al. (2016). Safety and efficacy of sorafenib therapy in patients with hepatocellular carcinoma: final outcome from the Chinese patient subset of the GIDEON study. Oncotarget. 7(6): 6639-6648.

23. Apostolidis L, Pfeiffenberger J, Gotthardt D, Radeleff B, Mehrabi A, et al. (2018). Survival of Hepatocellular Carcinoma Patients Treated with Sorafenib beyond Progression. Gastrointest Tumors5(1-2): 38-46.

24. Otsuka T, Nakashita S, Yanagita K, Ario K, Kawasoe H, et al. (2015) Factors Associated with Post-Progression Survival in Patients with Advanced Hepatocellular Carcinoma Treated with Sorafenib. Diseases. 3(2): 68-77.

25. Inghilesi AL, Gallori D, Antonuzzo L, Forte P, Tomcikova D, et al. (2014). Predictors of survival in patients with established cirrhosis and hepatocellular carcinoma treated with sorafenib. World J Gastroenterol. 20(3): 786-794.

26. Brunetti O, Gnoni A, Licchetta A, Longo V, Calabrese A, et al. (2019). Predictive and Prognostic Factors in HCC Patients Treated with Sorafenib. Medicina (Kaunas) 55(10): 707.

27. Berhane S, Fox R, García-Fiñana M, Cucchetti A, Johnson P (2019) Using prognostic and predictive clinical features to make personalised survival prediction in advanced hepatocellular carcinoma patients undergoing sorafenib treatment. Br J Cancer 121(2): 117-124.

28. Imai K, Takai K, Miwa T, Taguchi D, Hanai T, et al. (2019) Rapid Depletions of Subcutaneous Fat Mass and Skeletal Muscle Mass Predict 
Worse Survival in Patients with Hepatocellular Carcinoma Treated with Sorafenib. Cancers (Basel) 11(8): 1206.

29. Di Costanzo GG, Casadei Gardini A, Marisi G, Scartozzi M, Granata R, et al. (2017) Validation of a Simple Scoring System to Predict Sorafenib Effectiveness in Patients with Hepatocellular Carcinoma. Target. Oncol 12: 795-803.

\section{ISSN: 2574-1241}

DOI: 10.26717/BJSTR.2021.35.005713

Hend Ibrahim Shousha. Biomed J Sci \& Tech Res

(c) (†) This work is licensed under Creative

Submission Link: https://biomedres.us/submit-manuscript.php
30. Reig M, Torres F, Rodriguez-Lope C, Forner A, LLarch N, et al. (2014) Early dermatologic adverse events predict better outcome in HCC patients treated with sorafenib. J Hepatol 61: 318-324.

$\begin{array}{ll}\text { BIOMEDICAL } & \text { Assets of Publishing with us } \\ \text { RESEARCHES } & \text { - Global archiving of articles } \\ \text { - Immediate, unrestricted online access }\end{array}$

